\title{
Protective Role of Rosemary Ethanolic Extract on Thioacetamide Induced Hepatic Encephalopathy: Biochemical and Molecular Studies
}

\author{
Alshaimaa M. Said ${ }^{1 *}$, Rania M. Waheed ${ }^{2}$, Olla A. Khalifa ${ }^{3}$ \\ ${ }^{1}$ Biochemistry Department, ${ }^{2}$ Forensic Medicine and Toxicology Department, Educational Hospital, ${ }^{3}$ Animal Wealth Development Department, Faculty of \\ Veterinary Medicine, Benha University. 13736 Moshtohor, Toukh, Qaliobiya, Egypt. \\ Correspondence Author: Alshaimaa Mohammed Said, Biochemistry Department, Faculty of Veterinary Medicine, Benha University. 13736 Moshtohor, Toukh, \\ Qaliobiya, Egypt. \\ E-mail:- alshaimaa.said@fvtm.bu.edu.eg
}

Received date: 18 February 2019, Accepted date: 5 April 2019, Online date: 26 April 2019

Copyright: () 2019 Alshaimaa M. Said et al, This is an open-access article distributed under the terms of the Creative Commons Attribution License, which permits unrestricted use, distribution, and reproduction in any medium, provided the original author and source are credited.

\begin{abstract}
Background: Hepatic encephalopathy (HE) is a major health concern worldwide with a significant morbidity and mortality in addition to the economic burden. Oxidative stress, induced from exposure to various pollutants, with the resultant inflammation contributed to the pathogenesis of HE. Objectives: This study was conducted to evaluate the antioxidant and anti-inflammatory effects of rosemary ethanolic extract on thioacetamide (TAA) induced HE. Materials and Methods: Rats used in this study were divided into three groups: control group, TAA group received intraperitoneal (i.p) injection of TAA twice weekly for 12 weeks, rosemary treated group received i.p injection of TAA twice weekly and oral daily dose of rosemary ethanolic extract for 12 weeks. Results: The results revealed an obvious state of oxidative stress in liver and brain as evidenced by elevated malondialdehyde (MDA) and oxidized glutathione (GSSG) levels and lowered reduced glutathione (GSH) and total antioxidant capacity (TAC). Additionally, the concentration and gene expression of tumor necrosis factor- $\alpha$ (TNF- $\alpha$ ), interleukin- 6 (IL-6) and interleukin-10 (IL-10) indicating a significant inflammatory response. On the other hand, co-treatment with rosemary extract exhibited a significant improvement antioxidant capacities and inflammatory status of liver and brain. Moreover, the matrix metalloproteinase-1 (MMP-1) and paraoxonase-1 (PON-1) as fibrotic markers were analyzed proposing a possible anti-fibrotic activity of rosemary. Conclusion: it can be concluded that rosemary extract provide a powerful ameliorating effect against TAA induced HE owing to the antioxidant, anti-inflammatory and possible anti-fibrotic activities of its constituents.
\end{abstract}

Keywords: Hepatic encephalopathy, interleukin-10, interleukin-6, matrix metalloproteinase-1, rosemary, thioacetamide

\section{INTRODUCTION}

Hepatic encephalopathy is a profound systemic consequence of liver insufficiency with neuropsychiatric symptoms, and in severe cases, coma and death developed (Vilstrup et al., 2014). The mortality rate of HE ranging from 50-90\% of patients allover the world (Raghavan and Marik, 2006). Normally, the liver can detoxify endogenous and exogenous ammonia into urea. Once the liver fails, hyperammonemia occurs, and ammonia passes the blood-brain barrier (Felipo and Butterworth, 2002). Glutamine synthase catalyze the synthesis of glutamine which accumulates inside astrocytes leading to cerebral edema and intracranial hypertension with subsequent alterations in cerebral functions (Shawcross and Jalan, 2005).

Frequent unavoidable exposure to environmental pollutants, which are metabolized and detoxified in the liver, results in a state of oxidative stress, hepatic, renal and even neurotoxic effects. Thioacetamide (TAA) is a sulfur-containing compound widely used in technical applications and industries as leather, textile and paper production (Sharma et al., 2000). A single dose of TAA used in several experimental studies to induce acute liver injury while exposure to small doses of TAA used to develop chronic liver failure followed by HE (Waters et al., 2005).

Various side effects of pharmaceutical preparations used in the treatment of liver insufficiency trigger the need for searching for new safe and effective therapeutic agents. Since oxidative stress has been implicated in acute and chronic liver injury, the 
natural antioxidants are acceptable candidates for protection and management of liver injury and its subsequent neurologic effects (McDonough, 2003).

Rosmarinus officinalis, known as Rosemary and belong to the Lamiaceae family, cultivated now in many parts of the world after being restricted to the Mediterranean region only (Pérez et al., 2007). It is widely used as a flavouring agent and natural food preservative due to its potent antioxidant constituents (Santoyo et al., 2005). Moreover, rosemary has been used for a long time in folk medicine for the treatment of various diseases as peptic ulcer, gastrointestinal tract disturbances, biliary colic, renal colic, bronchial asthma, headache and epilepsy (Dorman et al., 2003). Several research studies revealed the active constituents of rosemary leaves. The dark green needle-like leaves contain phenolic diterpenes as carnosol, carnosic acid, rosmanol and phenolic acids as rosmarinic acid. These active compounds constitute a wide variety of biological activities as an antioxidant, antiinflammatory and anticarcinogenic agents (Del Bano et al., 2006).

The aim of the present experimental study was to assess the antioxidant and anti-inflammatory effects of rosemary ethanolic extract onTAA-induced hepatic encephalopathy in rats. Oxidative stress was assessed by measuring liver and brain levels of malondialdehyde (MDA), oxidized glutathione (GSSG), reduced glutathione (GSH) and total antioxidant capacity (TAC) in addition to hepatic matrix metalloproteinase-1 (MMP-1) and paraoxonase-1 (PON1) as fibrotic markers. Moreover, the concentration and gene expression of TNF- $\alpha$, IL- 6 and IL-10 were determined in liver and brain homogenate.

\section{MATERIAL AND METHODS}

\subsection{Chemicals}

Thioacetamide was purchased from Sigma-Aldrich, St. Louis, MO, USA.

\subsection{Preparation of rosemary ethanolic extract}

Rosemary dry leaves were purchased from the local market in Cairo, Egypt and grinded to a fine powder. The plant extract was prepared by addition of ethanol $70 \%$ to the fine powder in a firmly closed jar and let for 3-5 days at room temperature with vigorous shaking twice a day. The mixture was filtered using filter paper, and a rotatory evaporator was used to evaporate the alcohol and obtain the pure extract. The residues were re-extracted by the same method to get the whole constituents of the plant.

\subsection{Animals}

All experiments were approved by the Ethical Committee of Faculty of Veterinary Medicine, Benha University. Thirty male Wistar albino rat $(150 \pm 20 \mathrm{~g})$ were supplied by the animal house of Faculty of Veterinary Medicine, Benha University, Egypt. They were acclimatized in our animal facility for one week under controlled environmental conditions before the start of the experiment. Fresh daily supplies of food and tape water were served ad libitum.

\subsection{Experimental protocol}

Rats were randomly divided into three groups (10 animals per group) and treated for 12 consecutive weeks. The control group ( $1^{\text {st }}$ group): received saline i.p. twice weekly and considered as a control group. Thioacetamide group ( $2^{\text {nd }}$ group) received TAA $\left(200 \mathrm{mg} / \mathrm{kg}\right.$, i.p.) twice weekly to provoke HE (Furtado et al., 2012). Rosemary treated group ( $3^{\text {rd }}$ group) received TAA (200 $\mathrm{mg} / \mathrm{kg}$, i.p.) twice weekly and an oral daily dose of rosemary ethanolic extract $(200 \mathrm{mg} / \mathrm{kg}$ ) for 12 weeks (Sotelo-Felix et al., 2002). Tissue samples were collected twice during the experiment with six weeks interval.

The animals were fasted overnight and euthanized with diethyl ether. After sacrifice, liver and brain were quickly removed, washed three times with cold physiological saline and homogenized using phosphate buffered saline at $4{ }^{\circ} \mathrm{C}$ producing a $20 \%$ homogenate. In addition to homogenates, representative liver and brain specimens were kept in RNA later storage solution (Sigma-Aldrich) for RNA extraction once at the end of the experiment. Tissue homogenates and samples for RNA extraction were kept at $80^{\circ} \mathrm{C}$ till analyses.

\subsection{Assessment of oxidative stress markers}

The malondialdehyde (MDA), oxidized glutathione (GSSG), reduced glutathione (GSH) and total antioxidant capacity (TAC) were assayed as indices for oxidative stress in liver and brain using appropriate commercial kits (Biodiagnostic, Cairo, Egypt).

\subsection{Assessment of inflammatory markers}

Liver and brain tumor necrosis factor- $\alpha$ (TNF- $\alpha$ ), interleukin-6 (IL-6) and interleukin-10 concentrations were assayed using ELISA kits based on TNF- $\alpha$, IL- 6 and IL-10 monoclonal antibodies and converted to the TNF- $\alpha$, IL- 6 and IL-10 levels expressed as picograms per milligram tissue.

\subsection{Quantitative real-time polymerase chain reaction (RT-PCR) analyses of TNF- $\alpha$, IL-6 and IL-10 gene expressions}

Total RNA was extracted from the samples using the RNeasy Mini Kit (Qiagen). For One-Step RT-PCR procedures cDNA was synthesized from $(0.5 \mu \mathrm{g})$ RNA with the Invitrogen SuperScript ${ }^{\mathrm{TM}}$ II Reverse Transcriptase (Fisher Scientific, England, UK). Quantitative real-time PCR amplifications were performed with 2X SYBR Green RT-PCR reaction mix, in the thermocycler Rotor-Gene Q (Qiagen), under the following cycle conditions: cDNA synthesis 10 minutes at $50{ }^{\circ} \mathrm{C}$, Reverse transcriptase inactivation five minutes at $95{ }^{\circ} \mathrm{C}$, PCR cycling and detection ( 30 to 45 cycles) 10 seconds at $95{ }^{\circ} \mathrm{C}$ followed by 30 seconds at 55 ${ }^{\circ} \mathrm{C}$ to $60{ }^{\circ} \mathrm{C}$. Transcript quantities were normalized by GAPDH as a housekeeping gene. The following primers (Sigma-Aldrich) were used for cDNA amplification: 
Citation: Alshaimaa M. Said, et al., Protective Role of Rosemary Ethanolic Extract on Thioacetamide Induced Hepatic Encephalopathy: Biochemical and Molecular Studies. Australian Journal of Basic and Applied Sciences, 13(4): 1-6. DOI: 10.22587/ajbas.2019.13.4.1

GAPDH forward: CAATGAATACGGCTACAGCAAC and GAPDH reverse: AGGGAGATGCTCAGTGTTGG.

TNF- $\alpha$ forward: ATAACTGCACCCACTTCCCA and TNF- $\alpha$ reverse: GAGGCCATTTGGGAACTTCT.

IL-6 forward: GACTTCCAGCCAGTTGCCTTCTTG and IL-6 reverse: TGGTCTGTTGTGGGTGGTATCCTC.

IL-10 forward: ATAACTGCACCCACTTCCCA and IL-10 reverse: GGGCATCACTTCTACCAGGT.

\subsection{Assessment of hepatic fibrosis}

Liver matrix metalloproteinase-1 (MMP-1) and paraoxonase-1 (PON-1) concentrations were assayed using ELISA kits based on monoclonal antibodies against MMP-1 and PON-1 and converted to the MMP-1, and PON-1 concentration expressed as nanograms per gram tissue.

\subsection{Statistical analysis}

The values were expressed as the mean \pm standard error of the mean. A significant difference was used at the 0.05 probability level. One-way analysis of variance and the least significant difference test were used to differentiate the differences between treatments using the Statistical Package for Social science Software (Version 18, SPSS Inc., Chicago, IL, USA).

\section{RESULTS}

\subsection{Assessment of oxidative stress}

MDA, GSSG and GSH concentrations and TAC were taken as markers of oxidative status in liver and brain tissues. TAA significantly increased MDA and GSSG concentrations and decreased GSH content and TAC compared to the control group. Treatment with rosemary extract significantly reduced MDA, GSSG and enhanced GSH content and TAC compared to the TAA group. It is worthy to note that rosemary extract reversed such changes showing no significant differences from the control group at the end of the experiment in both organs (Table 1,2).

Table 1: Effect of rosemary ethanolic extract on antioxidant and fibrotic markers in the liver of TAA injected rats

\begin{tabular}{|c|c|c|c|c|c|c|c|}
\hline & Liver & MDA (nmol/g) & GSH (ng/g) & GSSG (Pg/g) & TAC (nmol/g) & PON-1 (ng/g) & MMP-1 (ng/g) \\
\hline \multirow{3}{*}{$\begin{array}{l}y \\
\frac{y}{d} \\
3 \\
0 \\
0\end{array}$} & $1^{\text {st }}$ group & $156.00 \pm 13.45^{c}$ & $326.67 \pm 19.10^{a}$ & $97.67 \pm 11.22^{c}$ & $236.00 \pm 15.72^{\mathrm{a}}$ & $247.33 \pm 15.98^{\mathrm{a}}$ & $220.33 \pm 13.78^{c}$ \\
\hline & $2^{\text {nd }}$ group & $358.00 \pm 25.54^{\mathrm{a}}$ & $108.00 \pm 15.72^{c}$ & $283.00 \pm 17.21^{\mathrm{a}}$ & $107.67 \pm 12.17^{\mathrm{c}}$ & $128.00 \pm 13.45^{c}$ & 354. \\
\hline & $3^{\text {rd }}$ group & $244.00 \pm 19.14^{b}$ & $220.33 \pm 15.51^{b}$ & $204.00 \pm 13.75^{b}$ & $178.00 \pm 13.00^{b}$ & $192.33 \pm 15.9$ & 289. \\
\hline \multirow{3}{*}{ 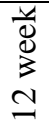 } & $1^{\text {st }}$ group & 135.3 & $308.00 \pm 22.50^{\mathrm{a}}$ & $138.33 \pm$ & $252.00 \pm 12.74^{\mathrm{a}}$ & $278.67 \pm 14.52^{a}$ & $181.67=$ \\
\hline & $2^{\text {nd }}$ group & $335.33 \pm 24.63^{a}$ & $156.33 \pm 18.00^{b}$ & $283.67 \pm 20.21^{\mathrm{a}}$ & $123.67 \pm 13.68^{b}$ & & 308 \\
\hline & $3^{\text {rd }}$ group & $178.67 \pm 19.41^{b}$ & $265.00 \pm 19.86^{a}$ & $156.67 \pm 16.90^{b}$ & $215.33 \pm 14.68^{a}$ & $261.33 \pm 15.62^{a}$ & $208.33 \pm 10.48^{b}$ \\
\hline
\end{tabular}

Mean values with different superscript letters in the same column are significantly different at $(\mathrm{P} \leq 0.05)$.

$1^{\text {st }}$ group; control group. $2^{\text {nd }}$ group; TAA group. $3^{\text {rd }}$ group; Rosemary treated group.

Table 2: Effect of rosemary ethanolic extract on antioxidant markers in brain of TAA injected rats

\begin{tabular}{|c|c|c|c|c|c|}
\hline & Brain & MDA (nmol/g) & GSH (ng/g) & GSSG (Pg/g) & TAC (nmol/g) \\
\hline \multirow{3}{*}{ 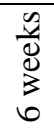 } & $1^{\text {st }}$ group & $130.33 \pm 12.35^{\mathrm{c}}$ & $265.33 \pm 13.84^{\mathrm{a}}$ & $110.33 \pm 8.35^{b}$ & $229.33 \pm 15.21^{\mathrm{a}}$ \\
\hline & $2^{\text {nd }}$ group & $355.33 \pm 32.99^{a}$ & $125.00 \pm 12.66^{b}$ & $259.00 \pm 15.13^{a}$ & $90.67 \pm 10.71^{c}$ \\
\hline & $3^{\text {rd }}$ group & $235.67 \pm 20.21^{b}$ & $168.67 \pm 12.73^{b}$ & $141.33 \pm 12.25^{b}$ & $140.33 \pm 11.86^{b}$ \\
\hline \multirow{3}{*}{$\begin{array}{l}\frac{y}{0} \\
\mathbb{d} \\
3 \\
\text { ป }\end{array}$} & $1^{\text {st }}$ group & $135.00 \pm 12.86^{b}$ & $247.67 \pm 11.39^{a}$ & $124.33 \pm 11.78^{b}$ & $237.00 \pm 16.37^{a}$ \\
\hline & $2^{\text {nd }}$ group & $332.00 \pm 24.06^{\mathrm{a}}$ & $141.00 \pm 13.75^{c}$ & $225.00 \pm 12.49^{\mathrm{a}}$ & $127.33 \pm 12.03^{b}$ \\
\hline & $3^{\text {rd }}$ group & $172.67 \pm 13.62^{b}$ & $223.33 \pm 15.88^{a}$ & $162.00 \pm 16.26^{b}$ & $203.67 \pm 14.25^{\mathrm{a}}$ \\
\hline
\end{tabular}

Mean values with different superscript letters in the same column are significantly different at $(\mathrm{P} \leq 0.05)$.

$1^{\text {st }}$ group; control group. $2^{\text {nd }}$ group; TAA group. $3^{\text {rd }}$ group; Rosemary treated group.

Table 3: Effect of rosemary ethanolic extract on inflammatory cytokines in liver and brain of TAA injected rats

\begin{tabular}{|c|c|c|c|c|c|c|c|}
\hline & & TNF- $\alpha(\mathrm{pg} / \mathrm{mg})$ & IL-6 (pg/mg) & IL-10 (pg/mg) & TNF- $\alpha$ & IL-6 & IL-10 \\
\hline \multirow{3}{*}{$\stackrel{\bar{D}}{. \bar{\nu}}$} & $1^{\text {st }}$ group & $85.89 \pm 4.50^{\mathrm{c}}$ & $27.48 \pm 3.60^{\mathrm{c}}$ & $15.49 \pm 1.04^{\mathrm{a}}$ & $1.02 \pm 0.02^{\mathrm{c}}$ & $1.00 \pm 0.02^{\mathrm{c}}$ & $1.02 \pm 0.01^{\mathrm{b}}$ \\
\hline & $2^{\text {nd }}$ group & $135.70 \pm 4.89^{\mathrm{a}}$ & $61.52 \pm 4.05^{\mathrm{a}}$ & $6.05 \pm 0.55^{c}$ & $3.36 \pm 0.23^{a}$ & $4.91 \pm 0.33^{\mathrm{a}}$ & $0.47 \pm 0.01^{\mathrm{c}}$ \\
\hline & $3^{\text {rd }}$ group & $106.95 \pm 7.58^{b}$ & $40.77 \pm 3.57^{b}$ & $10.59 \pm 1.10^{b}$ & $1.85 \pm 0.09^{b}$ & $3.66 \pm 0.32^{b}$ & $2.42 \pm 0.26^{\mathrm{a}}$ \\
\hline \multirow{3}{*}{ 汤 } & $1^{\text {st }}$ group & $106.30 \pm 3.09^{c}$ & $49.86 \pm 3.81^{c}$ & $32.95 \pm 1.45^{\mathrm{a}}$ & $1.00 \pm 0.01^{\mathrm{c}}$ & $1.00 \pm 0.02^{\mathrm{c}}$ & $1.02 \pm 0.01^{b}$ \\
\hline & $2^{\text {nd }}$ group & $224.43 \pm 4.91^{\mathrm{a}}$ & $86.08 \pm 3.82^{\mathrm{a}}$ & $13.29 \pm 1.11^{\mathrm{c}}$ & $4.64 \pm 0.33^{a}$ & $17.04 \pm 0.92^{\mathrm{a}}$ & $0.50 \pm 0.02^{\mathrm{c}}$ \\
\hline & $3^{\text {rd }}$ group & $121.13 \pm 1.51^{b}$ & $66.49 \pm 4.49^{b}$ & $22.50 \pm 1.67^{b}$ & $2.72 \pm 0.18^{b}$ & $4.66 \pm 0.31^{b}$ & $1.63 \pm 0.21^{\mathrm{a}}$ \\
\hline
\end{tabular}

Mean values with different superscript letters in the same column are significantly different at $(\mathrm{P} \leq 0.05)$.

$1^{\text {st }}$ group; control group. $2^{\text {nd }}$ group; TAA group. $3^{\text {rd }}$ group; Rosemary treated group.

\subsection{Assessment of inflammatory markers}

The concentrations of TNF- $\alpha$, IL- 6 and IL-10 in hepatic and cerebral tissues were analyzed immunoenzymatically at the end of the experiment. The mean concentrations of TNF- $\alpha$ and IL- 6 were significantly higher in the group that was given TAA 
Citation: Alshaimaa M. Said, et al., Protective Role of Rosemary Ethanolic Extract on Thioacetamide Induced Hepatic Encephalopathy: Biochemical and Molecular Studies. Australian Journal of Basic and Applied Sciences, 13(4): 1-6. DOI: 10.22587/ajbas.2019.13.4.1

compared to controls while the anti-inflammatory cytokine IL-10 was significantly decreased. On the other hand, co-treatment with rosemary extract significantly improved these changes when compared to the TAA group.

The abovementioned results were confirmed by the gene expression analyses of these cytokines. As shown in (Table 3), TAA treated rats showed significant up-regulation of TNF- $\alpha$ and IL-6 gene; meanwhile, IL-10 gene expression was significantly downregulated compared to the control value. On the contrary, treatment with rosemary extract markedly but not completely restored these alterations when compared to the TAA group.

\subsection{Assessment of liver fibrosis}

MMP-1 and PON-1 were immunoenzymatically measured to evaluate the impact of rosemary ethanolic extract on the extent of liver fibrosis. As shown in (Table 1), TAA injection showed a significant increase in MMP-1 and decreased in PON-1 in comparison to the control group. However, co-treatment with rosemary extract was able to demonstrate a clear attenuation to those alterations when compared to the TAA group. Interestingly, at the end of the experiment no statistically significant differences were found in both parameters between rosemary treated group and control group.

\section{DISCUSSION}

Oxidative stress and inflammation are proposed as possible mechanisms for the pathogenesis of hepatic encephalopathy. Therefore, the current experiment aimed at evaluating the potential protective effect of rosemary, a common spice known for its antioxidant and anti-inflammatory activities, against TAA-induced hepatic encephalopathy in rats. A remarkable protective effect of rosemary ethanolic extract was observed for the oxidative and inflammatory alterations elicited by TAA administration over the 12 weeks of the experiment. In the current study, TAA injection twice weekly for 12 weeks induced oxidative stress in liver and brain homogenate. These results were by the previous studies of (Fadillioglu et al., 2010; Mustafa et al., 2013). They reported the occurrence of oxidative stress in liver and brain tissues after TAA administration. Fadillioglu et al., (2010) attributed the reduced antioxidant status in three different parts of brain tissue to the hyperammonemia induced after TAA administration.

Thioacetamide metabolized by microsomal cytochrome-P-450 2E1 to thioacetamide-S-oxide. It is further metabolized, at least in part, to thioacetamide-S-dioxide by cytochrome-P-450 monooxygenase (Shapiro et al., 2006). Thioacetamide-S-dioxide is a highly reactive compound which binds to the tissue macromolecules leading to protein, lipid and DNA damage, the formation of reactive oxygen species (ROS). All of these results in exhaustion of antioxidant defences and depletion of reduced glutathione in hepatic tissue (Kang et al., 2008).

According to the information available, this experiment is the first to examine the efficacy of rosemary ethanolic extract against TAA-induced hepatic encephalopathy. Previous studies investigated the effect of antioxidants on TAA-induced HE since the oxidative stress contributed to the pathogenesis of HE (Fadillioglu et al., 2010). This is consistent with the current results which revealed that co-treatment with rosemary extract decreased the hepatic and cerebral oxidative stress in TAA treated rats (Table 1, 2). This effect was in agreement with the previous reports of (Amin and Hamza, 2005; Sotelo-Felix et al., 2002) in which rosemary extract alleviated the hepatotoxic effect of carbon tetrachloride and azathioprine respectively. They attributed the hepatoprotective effect of rosemary to its antioxidant property.

Two possible mechanisms can explain the antioxidant activity of rosemary extract. Firstly, the bioactive constituents of rosemary extract act as scavengers for the free radical reactive oxygen species, via their hydroxyl groups, therefore preventing lipid peroxidation and preserving reduced glutathione (Zegura et al., 2011). Secondly, they preserve the antioxidant status either by stimulating the synthesis of antioxidant enzymes or increasing their activity (Afonso et al., 2013). Wijeratne and Cuppett, (2007) suggested that, carnosic acid and carnosol mainly contributed to the antioxidant properties of rosemary extract. Also, the co-treatment with rosemary extract to rats injected with TAA exhibited a marked alleviation in the brain oxidative stress when compared to the TAA group. This came by the previous studies that suggested the oxidative stress as one of the significant mechanisms in the pathogenesis of HE (Fadillioglu et al., 2010). So, attenuating the oxidative stress induced by TAA metabolites played an active role in the improvement of brain antioxidant defences.

In the further part of the experiment, the concentration and gene expression of TNF- $\alpha$, IL- 6 and IL- 10 in liver and brain were analyzed. TAA injection induced a marked increase in the concentration and gene expression of TNF- $\alpha$ and IL-6 as inflammatory cytokines with a significant decrease in the anti-inflammatory IL-10. These results were in line with the previous study of Algandaby, (2018) who found a marked increase in hepatic TNF- $\alpha$ and IL- $1 \beta$ with up-regulation to nuclear factor- $\kappa \beta$ (NF- $\kappa \beta)$ and cyclo-oxygenase-2 (COX-2) expressions. The author explained these results due to the oxidative stress elicited by oxidants like TAA. The ROS activate NF- $\kappa \beta$ which in turn stimulates the production of pro-inflammatory cytokines (Racanelli and Rehermann, 2006). Additionally, NF- $\kappa \beta$ stimulates the production of COX-2 which also worsen the oxidative stress and inflammatory response (Hu, 2003). The pro-inflammatory cytokines secreted from activated macrophage and kuppfer cells could reach the brain and stimulate activated astrocytes to secrete cytokines (Chen et al., 2006).

In the present study, treatment with rosemary ethanolic extract reduced the inflammatory response in the liver and brain. This agreed with the previous investigation of Kuo et al., (2011) who studied the anti-inflammatory activity of carnosic acid, phenolic diterpenes of rosemary. They linked the anti-inflammatory activity of carnosic acid to the inhibition of NF- $\kappa \beta$. Also, Mengoni et al., (2011) attributed the anti-inflammatory activity of carnosic acid and carnosol of rosemary to the inhibition of COX-2 expression.

Pro-inflammatory cytokines released from kupffer cells in response to oxidative stress involved in the fibrotic process through activation of hepatic stellate cells (HSCs) and accumulation of extracellular matrix (ECM) (Wang et al., 2005). This was confirmed by the significant increase in MMP-1 in the current study. It is an endopeptidase that degrades ECM to maintain tissue homeostasis under normal physiological conditions (Knittel et al., 2000). The inflammation induced by TAA injection increased 
Citation: Alshaimaa M. Said, et al., Protective Role of Rosemary Ethanolic Extract on Thioacetamide Induced Hepatic Encephalopathy: Biochemical and Molecular Studies. Australian Journal of Basic and Applied Sciences, 13(4): 1-6. DOI: 10.22587/ajbas.2019.13.4.1

MMP-1 while co-treatment with rosemary extract effectively reduced the inflammatory response; therefore, the observed decrease in MMP-1 is related to the antioxidant and anti-inflammatory activities of rosemary. Also, PON-1 was affected by rosemary extract, an antioxidant enzyme hydrolyzes-phosphorogenic compounds and could be used as a marker of fibrosis (Marsillach et al., 2009). Co-treatment with rosemary extract attenuated the marked decrease in the PON-1. Taken together, the modulation in the fibrotic markers, MMP-1 and PON-1, proposed a possible anti-fibrotic activity to rosemary extract which requires further investigation to understand the underlying mechanisms.

\section{CONCLUSION}

The findings of this study indicate that treatment with rosemary ethanolic extract was effective against TAA-induced hepatic encephalopathy. This effect of rosemary may be attributed to the antioxidant and anti-inflammatory properties of one or more of its constituents. Further investigations are required to confirm the anti-fibrotic activity of rosemary and understand the underlying mechanism.

\section{AUTHOR CONTRIBUTION}

Conceived \& designed the experiments: Alshaimaa M. Said, Performed the experiments: Alshaimaa M. Said, Rania M. Waheed and Olla A. Khalifa, Analyzed the data: Alshaimaa M. Said, Wrote the paper: Alshaimaa M. Said, Rania M. Waheed and Olla A. Khalifa.

\section{Acknowledgement}

The authors would gratefully acknowledge the staff members in the Animal House of Biochemistry Department, Faculty of Veterinary Medicine, Benha University, Egypt for looking after the rats and for technical support in the implementation of this study.

\section{CONFLICT OF INTEREST}

This research did not receive any specific grant from any funding agency. The authors declare that there are no conflicts of interest.

\section{REFERENCES}

Afonso, M. S., A. M de O Silva, E. B Carvalho, D. P. Rivelli, S. B Barros, M. M. Rogero, A. M Lottenberg, R. P. Torres, and J. Mancini-Filho. 2013. "Phenolic compounds from Rosemary (Rosmarinus officinalis L.) attenuate oxidative stress and reduce blood cholesterol concentrations in diet-induced hypercholesterolemic rats." Nutrition \& Metabolism 10 (19):1-9. doi: 10.1186/1743-7075-10-19.

Algandaby, M. M. 2018. "Antifibrotic effects of crocin on thioacetamide-induced liver fibrosis in mice." Saudi journal of biological sciences 25 (4):747-54. doi: 10.1016/j.sjbs.2016.10.007.

Amin, A., and A. A. Hamza. 2005. "Hepatoprotective effects of Hibiscus, Rosmarinus and Salvia on azathioprine-induced toxicity in rats." Life Sci 77 (3):266-78. doi: 10.1016/j.lfs.2004.09.048.

Chen, S. W., Y. X. Chen, J. Shi, Y. Lin, and W. F. Xie. 2006. "The restorative effect of taurine on experimental nonalcoholic steatohepatitis." Dig Dis Sci 51 (12):2225-2234. doi: 10.1007/s10620-006-9359-y.

Del Bano, M. J., J. Castillo, O. Benavente-Garcia, J. Lorente, R. Martin-Gil, C. Acevedo, and M. Alcaraz. 2006. "Radioprotectiveantimutagenic effects of rosemary phenolics against chromosomal damage induced in human lymphocytes by gamma-rays." J Agric Food Chem 54 (6):2064-2068. doi: 10.1021/jf0581574.

Dorman, H. J. D., A. Peltoketo, R. Hiltunen, and M. J. Tikkanen. 2003. "Characterisation of the antioxidant properties of deodourised aqueous extracts from selected Lamiaceae herbs." Food Chemistry 83 (2):255-262. doi: https://doi.org/10.1016/S0308-8146(03)00088-8.

Fadillioglu, E., C. Gursul, and M. Iraz. 2010. "Effects of caffeic acid phenethyl ester on thioacetamide-induced hepatic encephalopathy in rats." Progress in neuro-psychopharmacology \& biological psychiatry 34 (8):1440-1445. doi: 10.1016/j.pnpbp.2010.07.034.

Felipo, V., and R. F. Butterworth. 2002. "Mitochondrial dysfunction in acute hyperammonemia." Neurochem Int 40 (6):487-491.

Furtado, K. S., M. G. Prado, E. Silva M. A. Aguiar, M. C. Dias, D. P. Rivelli, M. A. Rodrigues, and L. F. Barbisan. 2012. "Coffee and caffeine protect against liver injury induced by thioacetamide in male Wistar rats." Basic Clin Pharmacol Toxicol 111 (5):339-347. doi: 10.1111/j.1742-7843.2012.00903.x.

Hu, K. Q. 2003. "Cyclooxygenase 2 (COX2)-prostanoid pathway and liver diseases." Prostaglandins Leukot Essent Fatty Acids 69 (5):329-337.

Kang, J. S., H. Wanibuchi, K. Morimura, R. Wongpoomchai, Y. Chusiri, F. J. Gonzalez, and S. Fukushima. 2008. "Role of CYP2E1 in thioacetamide-induced mouse hepatotoxicity." Toxicol Appl Pharmacol 228 (3):295-300. doi: 10.1016/j.taap.2007.11.010.

Knittel, T., M. Mehde, A. Grundmann, B. Saile, J. G. Scharf, and G. Ramadori. 2000. "Expression of matrix metalloproteinases and their inhibitors during hepatic tissue repair in the rat." Histochem Cell Biol 113 (6):443-453.

Kuo, C. F., J. D. Su, C. H. Chiu, C. C. Peng, C. H. Chang, T. Y. Sung, S. H. Huang, W. C. Lee, and C. C. Chyau. 2011. "Antiinflammatory effects of supercritical carbon dioxide extract and its isolated carnosic acid from Rosmarinus officinalis leaves." J Agric Food Chem 59 (8):3674-3685. doi: 10.1021/jf104837w. 
Citation: Alshaimaa M. Said, et al., Protective Role of Rosemary Ethanolic Extract on Thioacetamide Induced Hepatic Encephalopathy: Biochemical and Molecular Studies. Australian Journal of Basic and Applied Sciences, 13(4): 1-6. DOI: 10.22587/ajbas.2019.13.4.1

Marsillach, J., J. Camps, N. Ferré, R. Beltran, A. Rull, B. Mackness, M. Mackness, and J. Joven. 2009. "Paraoxonase-1 is related to inflammation, fibrosis and PPAR delta in experimental liver disease." BMC gastroenterology 9 (3):1-13. doi: $10.1186 / 1471-230 X-9-3$.

McDonough, K. H. 2003. "Antioxidant nutrients and alcohol." Toxicology 189 (1-2):89-97.

Mengoni, E. S., G. Vichera, L. A. Rigano, M. L. Rodriguez-Puebla, S. R. Galliano, E. E. Cafferata, O. H. Pivetta, S. Moreno, and A. A. Vojnov. 2011. "Suppression of COX-2, IL-1beta and TNF-alpha expression and leukocyte infiltration in inflamed skin by bioactive compounds from Rosmarinus officinalis L." Fitoterapia 82 (3):414-421. doi: 10.1016/j.fitote.2010.11.023.

Mustafa, H. N., S. A. El Awdan, and G. A. Hegazy. 2013. "Protective role of antioxidants on thioacetamide-induced acute hepatic encephalopathy: biochemical and ultrastructural study." Tissue Cell 45 (5):350-362. doi: 10.1016/j.tice.2013.06.001.

Pérez, M. B. , N. L. Calderón, and C. A. Croci. 2007. "Radiation-induced enhancement of antioxidant activity in extracts of rosemary (Rosmarinus officinalis L.)." Food Chemistry 104:585-592. doi: 10.1016/j.foodchem.2006.12.009.

Racanelli, V., and B. Rehermann. 2006. "The liver as an immunological organ." Hepatology 43 (2 Suppl 1):54-62. doi: 10.1002/hep.21060.

Raghavan, M., and P. E. Marik. 2006. "Therapy of intracranial hypertension in patients with fulminant hepatic failure." Neurocrit Care 4 (2):179-189. doi: 10.1385/ncc:4:2:179.

Santoyo, S., S. Cavero, L. Jaime, E. Ibanez, F. J. Senorans, and G. Reglero. 2005. "Chemical composition and antimicrobial activity of Rosmarinus officinalis L. essential oil obtained via supercritical fluid extraction." J Food Prot 68 (4):790-795.

Shapiro, H., M. Ashkenazi, N. Weizman, M. Shahmurov, H. Aeed, and R. Bruck. 2006. "Curcumin ameliorates acute thioacetamide-induced hepatotoxicity." J Gastroenterol Hepatol 21 (2):358-366. doi: 10.1111/j.1440-1746.2005.03984.x.

Sharma, V. K. , R. A. Rendon, F. J. Millero, and F. G. Vazquez. 2000. "Oxidation of thioacetamide by ferrate(VI). ." Marine Chemistry 70 (1-3):235-242. doi: 10.1016/S0304-4203(00)00029-3.

Shawcross, D., and R. Jalan. 2005. "The pathophysiologic basis of hepatic encephalopathy: central role for ammonia and inflammation." Cell Mol Life Sci 62 (19-20):2295-2304. doi: 10.1007/s00018-005-5089-0.

Sotelo-Felix, J. I., D. Martinez-Fong, P. Muriel, R. L. Santillan, D. Castillo, and P. Yahuaca. 2002. "Evaluation of the effectiveness of Rosmarinus officinalis (Lamiaceae) in the alleviation of carbon tetrachloride-induced acute hepatotoxicity in the rat." J Ethnopharmacol 81 (2):145-154.

Vilstrup, H., P. Amodio, J. Bajaj, J. Cordoba, P. Ferenci, K. D. Mullen, K. Weissenborn, and P. Wong. 2014. "Hepatic encephalopathy in chronic liver disease: 2014 Practice Guideline by the American Association for the Study of Liver Diseases and the European Association for the Study of the Liver." Hepatology 60 (2):715-735. doi: 10.1002/hep.27210.

Wang, H., W. Wei, N. P. Wang, S. Y. Gui, L. Wu, W. Y. Sun, and S. Y. Xu. 2005. "Melatonin ameliorates carbon tetrachlorideinduced hepatic fibrogenesis in rats via inhibition of oxidative stress." Life Sci 77 (15):1902-1915. doi: 10.1016/j.lfs.2005.04.013.

Waters, N J., C J. Waterfield, R. D Farrant, E Holmes, and J K. Nicholson. 2005. "Metabonomic Deconvolution Of Embedded Toxicity: Application To Thioacetamide Hepato- and Nephrotoxicity." Chemical Research in Toxicology 18 (4):639-654. doi: 10.1021/tx049869b.

Wijeratne, S. S., and S. L. Cuppett. 2007. "Potential of rosemary (Rosemarinus officinalis L.) diterpenes in preventing lipid hydroperoxide-mediated oxidative stress in Caco-2 cells." J Agric Food Chem 55 (4):1193-1199. doi: 10.1021/jf063089m.

Zegura, B., D. Dobnik, M. H. Niderl, and M. Filipic. 2011. "Antioxidant and antigenotoxic effects of rosemary (Rosmarinus officinalis L.) extracts in Salmonella typhimurium TA98 and HepG2 cells." Environ Toxicol Pharmacol 32 (2):296-305. doi: 10.1016/j.etap.2011.06.002. 